\title{
ARTICLES
}

\section{COVID-19 vaccine online misinformation in Fiji Preliminary findings}

\begin{abstract}
Digital media opens a vast array of avenues for lay people to effectively engage with news, information and debates about important science and health issues. However, they have also become a fertile ground for various stakeholders to spread misinformation and disinformation, stimulate uncivil discussions and engender ill-informed, dangerous public decisions. During the COVID-19 pandemic, antivaccination social media accounts were proliferating online, threatening to further escalate vaccine hesitancy. The pandemic signifies not only a global health crisis, it has also proven to be an infodemic, characterised by many conspiracy theories. Prior research indicates that belief in health-related conspiracies can harm efforts to curtail the spread of a virus. This article presents and examines preliminary research findings on COVID-19 vaccine related misinformation being circulated on Fijian Facebook Forums.
\end{abstract}

Keywords: COVID-19, disinformation, Facebook, Fiji, misinformation, social media, vaccine, vaccine hesitancy, vaccination

\section{ROMITESH KANT}

La Trobe University

RUFINO VAREA

The University of the South Pacific

JASON TITIFANUE

La Trobe University

\section{Introduction}

-HE SPREAD of coronavirus disease COVID-19 worldwide in 2020 brought the modern world to an extraordinary standstill. The scientific community and world governments have responded by providing unprecedented opportunities for research related to COVID-19 (Lake, 2020). In the early days of the pandemic, researchers noticed the spread of misinformation and conspiracy theories, as well as unconfirmed information about COVID-19 
(Kouzy et al., 2020; Mian \& Khan, 2020). Brennen, Simon, Howard, and Nielsen (2020) noted that significant amounts of misinformation were created by modifying information whereby 'existing and often true information is spun, twisted, recontextualised, or reworked' (p. 1). Numerous conspiracy theories have also abounded which have sought to link COVID-19 to global elites. Although public epidemiological studies and other scientific work have been conducted on COVID-19, a large amount of information has caused the public to be confused as to which sources of information are reliable (Lima, Lopes, \& Brito, 2020).

The World Health Organisation (WHO) declared the spread of the virus a 'pandemic' on 11 March 2020. During this global pandemic, many countries implemented blockade measures, and at the time of writing, some countries are still doing so. Approximately 4.5 million people have died globally, and 216 million people were infected (World Health Organisation, 2021). During this period, large amounts of COVID-19 misinformation have circulated. This has resulted in WHO Director-General Tedros Adhanom Ghebreyesus referring to the crisis as an 'infodemic', that is a situation when people face an overload of information that might be true or false, challenging what to believe (Hao \& Basu, 2020).

This infodemic has also had an impact on the uptake of COVID-19 vaccines. Rumours and conspiracy theories have been identified as triggers for the general public's COVID-19 vaccine hesitancy and acceptance (Freeman et al., 2020). Numerous conspiracy theories have also sought to link the COVID-19 pandemic to a universal plan by global elites. This has been in keeping with the suggestion by Sunstein and Vermeule (2009) that conspiracy theories typically seek to 'explain some event or practice by reference to the machinations of powerful people, who attempt to conceal their role (at least until their aims are accomplished)' (p. 205). Vaccination hesitancy has been based on false claims that the COVID-19 vaccines contain infertility agents or that they can spread an infectious virus such as the Human Immunodeficiency Virus (HIV) (Aylward \& Heymann, 2005; Jegede, 2007). In the past, harmful, and unsubstantiated claims about the effectiveness of vaccines have influenced vaccine hesitancy.

Against this backdrop, social media platforms have become a common source of health information. During a pandemic, people can use social media to raise awareness of diseases, transmission, and prevention mechanisms (M. S. Islam et al., 2020; Lavorgna, Ippolito, Esposito, Tedeschi, \& Bonavita, 2017). Public health information on COVID-19 shared on online platforms is often reinforced by rumours and conspiracy theories. These rumours and conspiracy theories are not always based on scientifically accepted evidence (Lavorgna et al., 2017). When searching for health information on online platforms, the use and sharing of misinformation or baseless scientific data is a behaviour that may endanger public health efforts to curb the spread of the actual virus ((Seneviratne \& Muppidi, 
S, 2021; Waszak, Kasprzycka-Waszak, \& Kubanek, 2018). People often share concerns, mistrust, and rumours about vaccines on social media before being detected through traditional surveillance systems, such as event-based surveillance (Fernández-Luque \& Bau, 2015). Therefore, monitoring social media data has been identified as one of the best methods for tracking misinformation in real-time and possible ways to dispelling misinformation and improve vaccine acceptance.

A UNESCO Policy Brief provides two typologies for understanding the COVID-19 infodemic/ disinfodemic: First, it identifies nine important themes and four major format types linked with COVID-19 misinformation. Themes include deception, political assaults on journalists, and misrepresenting legitimate independent journalism as 'fake news' (Posetti \& Bontcheva, 2020). Disinformation infiltrators and coordinated campaigns use highly emotive narrative structures and memes, forged, fraudulently altered, or decontextualised pictures and videos, fake websites, data sets, and sources (Robie \& Krishnamurthi, 2020, p. 181).

Thus, this article examines the dissemination of COVID-19 vaccine-related misinformation and conspiracy theories on Fiji social media. Based on social media data collected over a three-month (April-June 2020) period, this article presents the preliminary findings of the research. It provides a discussion of sources and types of COVID-19 vaccine related misinformation on social media. Additionally, critical thematic narratives that have emerged from the social media data are identified and examined.

\section{Vaccine content on social media}

More recently, the widespread increase of COVID-19 and the resultant global pandemic has become a focus of intense social media discourse with Twitter reporting a COVID-19 related tweet every millisecond and the hashtag \#coronavirus surging to become the second most used in 2020 (Cinelli et al., 2020; Josephson \& Lambe, 2020). Unfortunately, false, and misleading information about COVID-19, potentially dangerous treatments, and eventual vaccination continue to grow on social media platforms. 'Infodemic' was the subject of an early COVID-19 study by Cinelli et al. (2020), who used epidemic modelling to the spread of information on multiple platforms to determine fundamental reproduction numbers for the 'transmissibility' of postings on each platform. Additionally, irrespective of platform, there were no significant differences between the disseminating patterns of information considered questionable compared with reliable ones. There is also growing worry that vaccine-related conversations are not confined to legitimate human accounts. Broniatowski et al. (2018) looked at how accounts belonging to robots (software programmes which create automated material) and trolls (internet accounts that falsify the user's identity and whose goal is to provoke conflict) operate on Twitter.

It is worth noting that the current trends in COVID-19 vaccine discourse 
bear a striking similarity to historical trends. Vaccine discourse on social media has had time to evolve, with such trends in discourse often coinciding with real-world public health events (Gunaratne, Coomes, \& Haghbayan, 2019). For instance, Gunaratne et al. (2019) demonstrated that anti-vaccine discourse on Twitter experienced a significant surge in 2015, coinciding with the 2014-2015 measles outbreak, publication of the anti-vaccine book Vaccine Whistleblower (\#cdcwhistleblower), and the release of the film Vaxxed (\#vaxxed). It also demonstrates that pro and anti-vaccine content may also naturally disseminate into distinct communities, possibly due to self-selection on social media, further enhanced by online algorithms, amalgamating like-minded communities to contrasting online information and content. For example, anti-vaccine content on Twitter largely coalesced into a community centred around \#cdcwhistleblower and \#vaxxed proponents, while pro-vaccine content primarily centred around the hashtag \#vaccineswork (Gunaratne et al., 2019; Ortiz-Ospina, 2019). Content appears to transfer between users who share similar sentiments regarding vaccination but rarely across those with differing opinions, suggesting the structure of such platforms may give the illusion of debate, but in practice mainly serves to reinforce previously held opinions rather than the consideration of new ones (Yuan, Schuchard, \& Crooks, 2019). Such ideological isolation may limit the ability of public health to promote vaccination on social media (Yuan et al., 2019).

\section{COVID-19 outbreak and vaccination status in Fiji}

COVID-19 was first identified in Fiji on 19 March 2020. After containing the spread and avoiding a community outbreak of the deadly virus for almost a year, Fiji reported its first case in early April 2021 and is now confronting the second wave of COVID-19. Since the first case was detected on March 19, 2020, 46,211 positive cases have been reported and 489 deaths as of August 31, 2021. Of these, 99.9 percent of positive cases and 99.5 percent of deaths have been recorded in this second wave outbreak (Fiji Ministry of Health and Medical Services, 2021c). Fijians are suffering from COVID-19's knock-on consequences in a variety of ways, and the epidemiological situation has been rapidly deteriorating; the Greater Suva Area (Lami, Suva, and Nausori) were designated 'Medical containment zones' on Viti Levu by the Fijian Government on 26 April 2021 (Naidu, 2021). Since then, travel to and from these places has been prohibited. COVID-19 is a significant concern for the Fijian Government, and vaccination efforts are seen as one of the best ways to facilitate a return to pre-pandemic lives. As stated by the Fijian Government and Ministry of Health $(\mathrm{MoH})$ :

The health and wellbeing of all Fijians are paramount. The COVID-19 vaccines are crucial for protection against the deadly global pandemic. 
The Vaccine is a worldwide effort to fight against the COVID-19 virus. This is a huge step back to normality for Fiji and its people with hopes that our international borders will open to visitors, restoring the livelihoods for thousands of Fijians, who for eons depended on the tourism sector. (Fiji Ministry of Health and Medical Services, 2021a)

For the protection of all Fijians against the COVID-19 virus, the AstraZeneca COVID-19 vaccine has been approved for use in Fiji for those aged 18 years and older. More recently, the Moderna vaccines were approved for Fijians with specific medical or health conditions that would prevent them from receiving the AstraZeneca vaccine (Fiji Ministry of Health and Medical Services, 2021b). It is suggested that the vaccination would be given to the priority groups initially; however, with bilateral partners commitments to supply Fiji's vaccination needs coupled with the massive community outbreak, the Fijian Government made doses available to the general population (Fiji Ministry of Health and Medical Services, 2021b).

The vaccination campaign began in March 2021, and Fiji became the first country in the Pacific Islands to receive COVID-19 vaccine doses shipped via the COVAX facility. Fiji is expected to receive 100,800 doses of the Oxford University/AstraZeneca COVID-19 vaccine as its initial provision under COVAX (World Health Organisation, 2021). In addition to the vaccines from the COVAX facility, the Indian Government provided 100,000 doses on March 29 (Fijian Government, 2021), the Australian Government has delivered 860,000 doses from a commitment to providing around one million vaccines to Fiji (Vacala, 2021), while the New Zealand Government has provided 100,000 doses from the commitment to supplying 500,000 doses (Fiji Ministry of Health and Medical Services, 2021d). As of 1 September 2021, 558,994 first doses have been administered, whereas 266,608 people are fully vaccinated, i.e., have received their second doses (Fiji Ministry of Health and Medical Services, 2021e).

\section{Figure 1: Confirmed COVID-19 cases in Fiji, 2021}

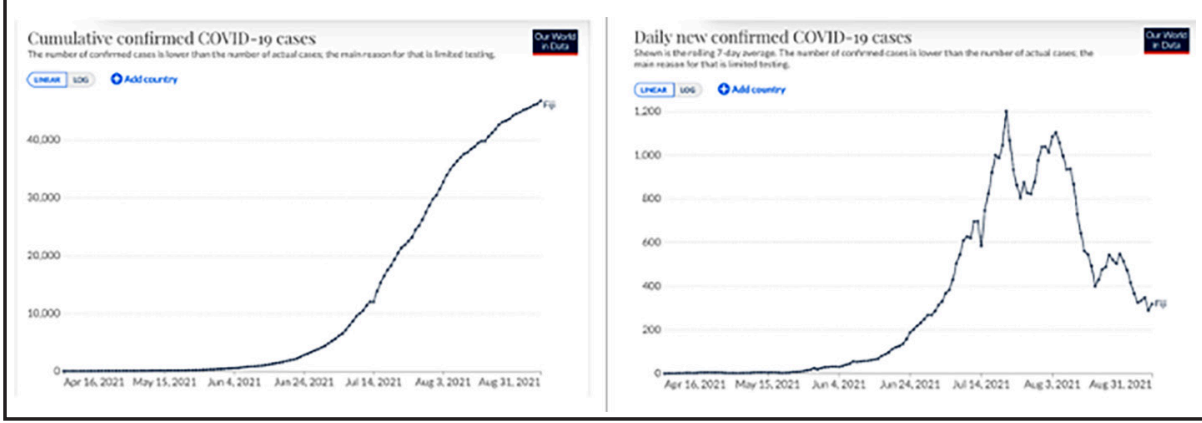

Note: Cumulative and daily confirmed COVID-19 statistics as at 31 August 2021. Source: John Hopkins University CSSE COVID-19 Data, https://ourworldindata.org/coronavirus/country/fiji 


\section{Figure 2: COVID-19 vaccination rates in Fiji, 2021}

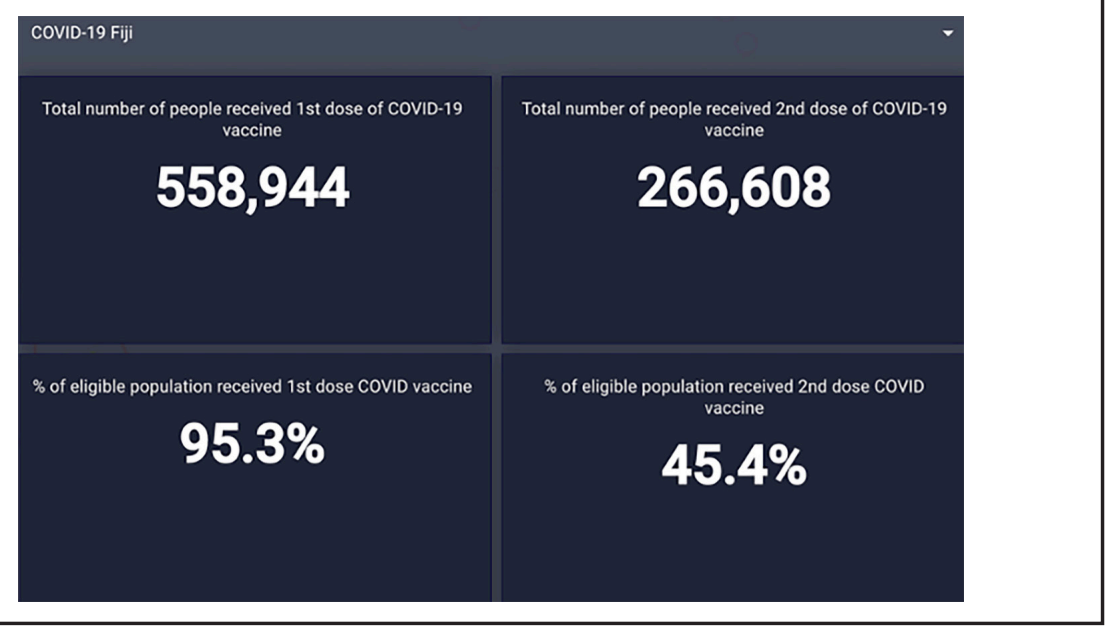

Note: COVID-19 vaccination rates in Fiji (as at 31 August 2021). Source: Fiji Ministry of Health and Medical Services, Vaccine Dashboard, https://tupaia.org/supplychain_fiji/FJ/COVID-19per cent20Fiji?overlay=FJ_COVID_TRACKING_Dose_2_District_Percentage_Vaccinated

\section{Data collection and analyses}

This study employed an interpretivist epistemological position as the aim was not to test the hypothesis but rather to understand and generate theory, then explain or prove the hypothesis. Our analysis used a grounded theory approach. We collected and analysed Facebook interactions data without a predefined theory, allowing concepts and ideas to emerge naturally (Ferrante, Shaw, \& Scott, 2011; Glaser \& Strauss, 1967).

To achieve the purpose of this study, we sourced the data from two popular and influential Facebook groups that have amassed many members in Fiji: Chat $\left(\right.$ Fiji) ${ }^{1}$ (more than 250,000 members) and Fiji Exposed Forum ${ }^{2}$ (more than 72,000 members). The data content was categorised according to its source (i.e., who initiated the post; host generated vs user-generated). The content was then analysed for distinct themes and concepts and their primary functions, including platform reaction features (like, care, angry, humour, love).

Discourse and content analysis has been applied, and posts/discussions regarding misinformation about different aspects of the outbreak between Facebook group members were analysed. We used predetermined themes and other inductive codes to independently extract and analyse the Facebook posts to determine major content themes for this study.

\section{A summary of data collected}

A total of 387 Facebook posts were analysed from Chat (Fiji) (67per cent) and Fiji Exposed Forum (33per cent) and were identified according to specific parameters of public interests in these virtual spheres (percentage of total 
posts analysed): China and Wuhan (31per cent), 5G (24per cent), Bill Gates and Fiji Index Patient (9per cent), Illuminati (6per cent), New World Order (17per cent), Vaccine (8per cent), Dead Birds (5per cent).

\section{Results and discussion}

\section{Theme 1: Fake news from international sources}

There had already been many conspiracy theories and mis/disinformation about coronavirus (Kant \& Varea, Forthcoming, 2021). With the advent of vaccination programmes in Fiji, false and misleading information about vaccines emerged and began to spread on social media platforms. Much of the misinformation was based on international sources and fed into the familiar global conspiracy narratives relating to vaccines. Anti-vaxxer groups and individuals tried to increase vaccine hesitancy with conspiracy theories ranging from the highly farfetched to the well-articulated pseudo-scientific claims.

Among the array of conspiracy narratives were claims that the vaccine would damage DNA or permanently alter genes. Numerous videos and images were shared claiming that vaccination turned individuals into genetically modified humans or would even turn one into a monkey. Other false claims included the vaccine allegedly containing chips to monitor the public. False information about significant side effects of vaccines caused many to be fearful of taking the shot. Some fake news claimed that the vaccine has all types of extreme side effects, including miscarriage and infertility. Others contended that one might get the coronavirus from the vaccine itself.

The dissemination of fake news has become extensive and effective, so much so that even government officials and public influencers engage in the proliferation of misinformation to their audiences or followers on social media to suit their agenda or build on social capital (Apuke \& Omar, 2021). A study by Chadwick and Vaccari (2019) found that close to half of online users sharing news reported having, at least at some point, shared misinformation. This demonstrates how misinformation and fake news can be very influential/persuasive (especially as a hedonic information system) (Islam, Laato, Talukder, $\&$ Sutinen, 2020). In 2020, the scale of responses by independent fact-checkers to online misinformation and fake news rose more than 900 per cent from January to March alone, signalling the online infodemic resurgence (Brennen et al., 2020). Social media platforms like Facebook and Twitter responded to flagged posts by independent fact-checkers deemed false by removing them or attaching warnings to the content.

\section{Theme 2: Lack of sufficient and transparent information}

Another reason that can lead to vaccine hesitancy is the lack of transparent, accessible, and correct information about vaccine safety and efficacy data. 


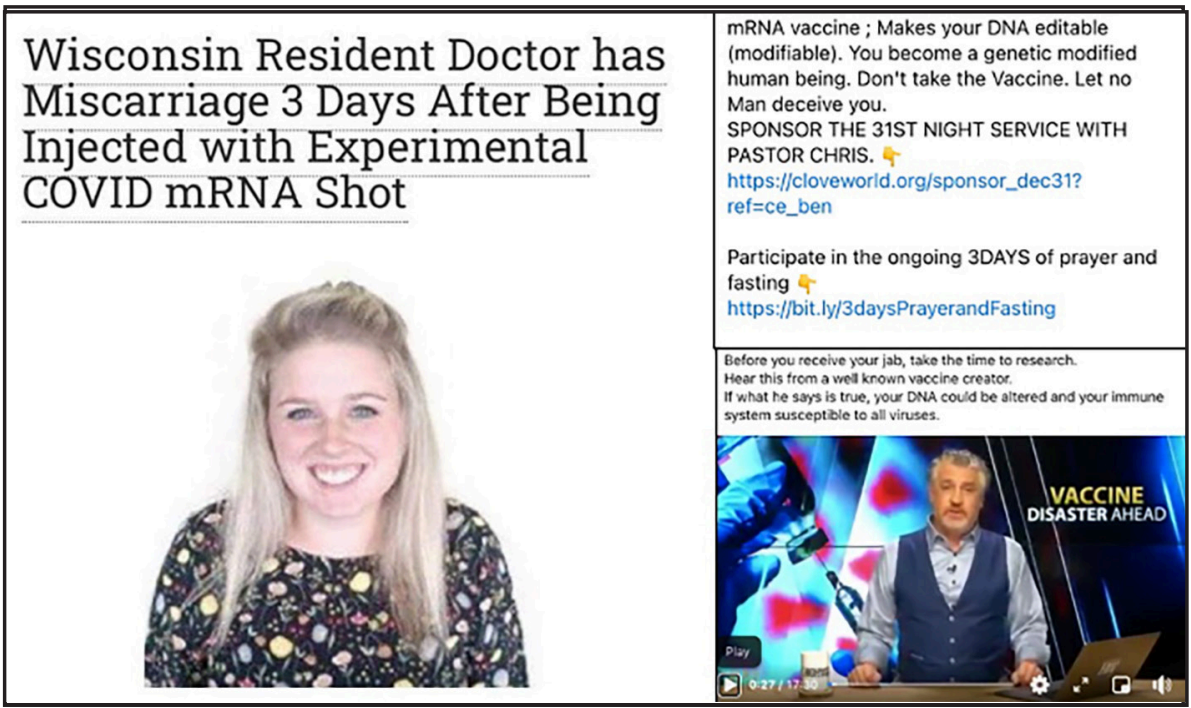

Figure 3: Collage of international COVID-19 vaccination claims circulated on

Chat Fiji. Source: CHAT (FIJI)

There have been doubts about the usefulness and safety of COVID-19 vaccines, which were rapidly up-scaled in research and development due to the situation's urgency.

Another factor is the relatively short timeline in information (i.e., temporal knowledge) about the side effects of the COVID-19 vaccines. Since it has been just a few months before its rollout, a significant proportion of people are still hesitant over the vaccines, which they believe may have higher risks in the longterm than if they were to survive COVID-19. A significant reason which might be increasing vaccine hesitancy is anecdotal 'cause-and-effect' rumour. There were even concerns raised that government officials were not being seen to be the first to receive vaccines. Posts abounded calling on government ministers to take the lead, with one such post stating,

It would have been a good sign if the PM was to be the first to receive the vaccine shots along with his cabinet members instead it's like they are avoiding getting vaccinated.

Additionally, a meme circulated stating that vaccines should be tested on government officials (Figure 4).

Misleading news linking vaccines to specific communities and religions also spread on socialmedia. Some claims posited that the coronavirus vaccines contained animal products or tissueandDNA from an aborted foetus through unpublished or debunked public health journal articles or grey literature, mainly from anti-vaxxers media content (Reuters, 2021). 
The data also showed that some individuals believed that their faith would be sufficient to sustain or restore their health and wellbeing. Therefore, there would be absolutely no need for vaccines. Some religious leaders spreading conspiracy theories about vaccines, claimed the vaccines are unnatural and thus ungodly. United States-based churches and evangelical ministries with large online followings - as well as Christian influencers on Facebook, Instagram, TikTok, Twitter and YouTube - have been making false claims that vaccines contain microchips that the world governments wished their citizens to have. Additionally, these evangelical influencers are construing associations between vaccine ingredients and demonic or paganistic potions. Insinuations were also made about how coronavirus vaccines and masks contained or herald the 'mark of the beast'. This is a reference to an apocalyptic passage (Chapter 13) from the Book of Revelation that suggests

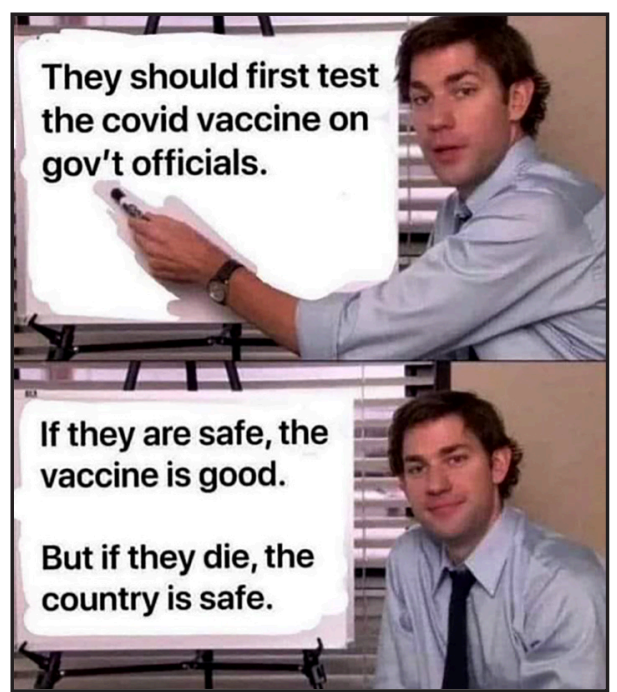

Figure 4: Meme calling for vaccines to be tested on government officials. Source: FIJI EXPOSED FORUM Theme 3: Religious factors that the Antichrist will test Christians by making them accept a mark on their foreheads or right hand to buy or sell (Eykel, 2021).

Many spiritually led individuals who have been exposed to threats such as in this health crisis use 'hope' in a deity or higher power to feel a sense of security and protection, thus using this belief as a survival strategy. The development of this level of personal confidence in their spirituality prioritises public health advisories and warnings that should be taken with more seriousness (Kowalczyk et al., 2020). For example, one Facebook post mentioned,

COVID.19 it is finish in Jesus name (sa oti) ....amen

while another stated,

I'm not scared of coronavirus.. he knows the cure.. Jesus Christ the Lord of this world and everything.

\section{Discussion}

Conspiracy theories are a significant part of vaccination hesitancy that can't be overlooked. Considering the COVID-19 epidemic and the uncertainty and vulnerability it caused, conspiracy theories have proliferated. Anti-vaccine conspiracy theories 
raise a host of needless fears about the risks of vaccines and lead to an undermining of people's confidence in the Government, which drives down vaccination rates. For the Fijian authorities, disinformation and vaccination reluctance have been a massive issue even before the pandemic.

While vaccination is one of the possible methods of reducing COVID-19 viral transmission, vaccinating everyone is a logistical issue, as is the case with many other diseases. Unfortunately, there were few common problems faced during the large-scale deployment of the COVID-19 vaccination campaign. Because of Fiji's remoteness and lack of technological development, the immunisation program was implemented without any significant difficulties regarding stakeholders or political concerns. On the other hand, fake news on social media platforms such as Facebook, Viber, TikTok and Instagram were

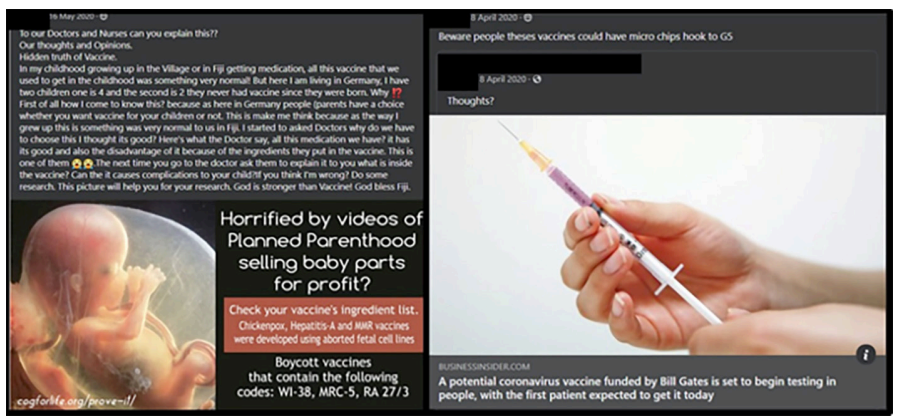

Figure 5: Collage of Facebook posts from Chat (Fiji) relating to vaccine misinformation discovered.

While basic facts about the virus are widely known, certain false and harmful narratives about the pandemic remain prominent offline and online. Most citizens are aware of simple preventative measures, but rumours and conspiracy theories are still prevalent on social media, including anti-5G narratives that overlap with dangerous anti-vaccine theories. The COVID-19 pandemic has highlighted how social media and online platforms drive public discourse, risk perception, and trust in institutions. While some Pacific Island countries and territories (apart from Fiji, French Polynesia, Guam and Papua New Guina) have mostly avoided severe outbreaks of the virus, they remain vulnerable to spreading false and harmful COVID-19 information on social media platforms. As the region's leaders prepare for vaccine distribution in 2021 and beyond, it is essential to ask why and how COVID-19 misinformation spread on social media in the region, and assess the degree to which this could impact vaccination efforts going forward (Kant, Jorari, \& Cain, 2021).

Social media also enabled international conspiracy theories about COVID-19 to be imported, adapted, and reconfigured to fit local events in Fiji. A report by the Asia Foundation found that:

[T]he public in Fiji benefits from access to a range of authoritative information sources, including official reporting transmitted through traditional 
media and social media platforms. Overt denial of COVID-19 is relatively low (about 6 percent say the virus is a 'hoax'), and high awareness of recommended protective measures. Trust and satisfaction in coverage of COVID-19 by the mainstream media and the government and police are also high. All these factors will support efforts toward a successful rollout of the COVID-19 vaccine. At the same time, public confidence in Fiji has been tested by the proliferation of false and harmful online narratives. About 68 percent of Fijian Facebook users and about 58 percent of messaging application users say they 'frequently' see COVID-19 misinformation on these platforms. (Kant, Jorari, \& Cain, 2021, p. 25)

The initial data collected and presented in this article is validated by two perception studies on rollout of COVID-19 vaccines in Fiji conducted by two nongovernmental organisations: the Fiji Women's Rights Movement (FWRM) and Dialogue Fiji.

In the first study, the Fiji Women's Rights Movement found that women in Fiji generally accept ( 84 percent) COVID19 vaccinations. Information on COVID-19 was mostly found on the Fijian Ministry for Health website (74 percent), followed by social media platforms such as Facebook and Instagram (73 percent). Social media was also a source of anti-vaccine messaging for many women who participated in this research. They cited vaccine safety concerns, distrust in the government, and misinformation about the vaccination on social media platforms as reasons for their vaccine hesitation. The research also found that religious views did not significantly influence women's vaccination uptake (Fiji Women's Rights Movement, 2021).

In another study on vaccine acceptance in Fiji, the research found that around 79 percent of the participants indicated that they would either get (71 percent) or probably get (8 percent) the vaccine when given the opportunity (Kumar, 2021). The report further found that females usually accepted vaccines at a higher percentage ( 74.9 percent) than males ( 68.5 percent). The COVID-19 vaccine had a higher acceptance rate among Indo-Fijians (84.1 percent) than the Rotumans (69.4 percent) and was the lowest in the iTaukei (52 percent). Vaccine acceptance was influenced by religion. There was a large discrepancy in the rates of vaccination among religious groups: for example, Muslims (88.6 percent) and Hindus (83.4 percent) were far more likely to be vaccinated than Christians, who were the most vaccine-hesitant (14.8 per cent) and had the lowest levels of acceptability (59.2 percent) (Kumar, 2021).

The influence of extreme religious teachings concerning the preservation of the natural body and the respect over the intent of a grand creator of humankind has been an amplifier of vaccine hesitancy/rejection, especially in ultra-religious societies like Fiji. According to Kant and Varea (2021), there is a widespread conviction in Fiji that religion plays a critical role in preserving health and welfare 
and, as a result, the assurance of vaccines to keep one in good health does not measure fairly against their belief in the absolute assurance they would receive from a spiritual being. Christian influencers, including religious leaders, shared conspiracy theories about vaccines via social media platforms (Facebook, TikTok, Instagram, and YouTube), associating COVID-19 vaccines with demonic potions and the 'mark of the beast', a plausible explanation for the vaccine's low acceptance rates among Christians in Fiji (Kant \& Varea, 2021).

Vaccine hesitancy frequently results from a lack of assurance in health care systems, governments, and public health agencies that give competent, expert advice about vaccines and COVID-19. The Dialogue Fiji study found that just over 3 in 4 people had high (52.2 percent) or moderate (24.6 percent) levels of trust in the public health agencies. In contrast, 23.1 percent indicated they had little to no confidence in the agencies that provide COVID-19 vaccine-related information. The World Health Organisation was the most trusted source for COVID-19 vaccine-related information, followed by the Fijian Government (50 percent), mass media (41.6 percent), online health websites (31.2 percent), health care professionals (29.6 percent) and social media (24.1 percent) (Kumar, 2021).

\section{Conclusion}

COVID-19 and the crises it precipitated have provided ideal ground for the development of new conspiracy theories. While some of them, like as the link between $5 \mathrm{G}$ and the epidemic's spread, have faded over time, others, such as human engineering of the virus in a Wuhan laboratory, phantom illness treatments without scientific basis, and purposefully manipulated vaccinations, have survived to the present day. Our preliminary findings further support the evidence that trust and conspiracy beliefs predict vaccine hesitancy, both generally and for COVID-19 precisely. Concerns about the origin of the virus and conspiracy theories about vaccine development should raise a red signal and warn policymakers and media outlets about the dangers of disseminating disinformation (Robie, 2021). If these conspiracy theories are not addressed by fact-checking and evidence-based scientific knowledge, the repercussions for public health might be more dire.

Government and health authorities should be aware of anti-vaccine campaigns and take necessary actions. Necessary services should be provided in areas with high illiteracy rates or poverty to help those people get vaccinated. Spreading the truth about the harmful effects of not taking the COVID-19 vaccine can help in lowering vaccine hesitancy. A balance needs to be maintained in reporting incidents like deaths or side effects that might not be related to vaccines. Mis/disinformation spread on national media outlets about the virus or vaccine should be condemned. Boosting transparency and the spread of accurate and sufficient information related to the virus and vaccines can help in mitigating 
peoples' fears and doubts. Therefore, Government needs to be more upfront in providing the latest information about COVID-19 vaccines. Public health authorities should handle public concerns. A communication helpline should be developed to explain their fears and doubts about vaccines and gain insights into the situation. Religious and opinion leaders can help encourage their followers to get vaccinated. Policymakers and public health officials need to develop targeted health communication strategies for subgroups with high vaccine hesitancy. Only with a collaborative effort from government, policymakers, public health institutions, medical practitioners, scientists, researchers, media, fact-checkers, and the citizens themselves can we survive this pandemic.

\section{Notes}

1. Chat (Fiji): https://www.facebook.com/groups/137127366336030

2. Fiji Exposed Forum: https://www.facebook.com/groups/164990380908494

\section{References}

Apuke, O. D., \& Omar, B. (2021). Fake news and COVID-19: Modelling the predictors of fake news sharing among social media users. Telematics and Informatics, 56, 101475. https://doi.org/10.1016/j.tele.2020.101475

Aylward, R. B., \& Heymann, D. L. (2005). Can we capitalise on the virtues of vaccines? Insights from the polio eradication initiative. American Journal of Public Health (AJPH) 773-777.

Brennen, J. S., Simon, F., Howard, P. N., \& Nielsen, R. K. (2020). Types, sources, and claims of COVID-19 misinformation. The Reuters Institute for the Study of Journalism, p. 1-13.

Broniatowski, D. A., Jamison, A. M., Qi, S., AlKulaib, L., Chen, T., Benton, A., Quinn, S. C., Dredze, M. (2018). Weaponized health communication: Twitter bots and Russian trolls amplify the vaccine debate. American Journal of Public Health, 108, 1378-1384. https://doi.org/10.2105/AJPH.2018.304567

Chadwick, A., \& Vaccari, C. (2019). News sharing on UK social media: Misinformation, disinformation, and correction. Retrieved on May 11, 2021, from https://repository. lboro.ac.uk/articles/report/News_sharing_on_UK_social_media_misinformation_disinformation_and_correction/947 1269

Cinelli, M., Quattrociocchi, W., Galeazzi, A., Valensise, C. M., Brugnoli, E., Schmidt, A. L., . . S Scala, S. (Producer). (2020). The COVID-19 social media infodemic. Retrieved from https://arxiv.org/abs/2003.05004.

Eykel, E. M. V. (2021, April 7). No, the COVID-19 vaccine is not linked to the mark of the beast - but a first-century Roman tyrant probably is. The Conversation. Retrieved on August 30, 2021, from https://theconversation.com/no-the-covid-19-vaccine-is-notlinked-to-the-mark-of-the-beast-but-a-first-century-roman-tyrant-probably-is-158288

Fernández-Luque, L., \& Bau, T. (2015). Health and social media: Perfect storm of information. Healthcare Informatics Research, 21(2), 67-73.

Ferrante, J. M., Shaw, E. K., \& Scott, J. G. (2011). Factors influencing men's decisions regarding prostate cancer screening: A qualitative study. Journal of Community Health, 36(5), 1-6. 
Fiji Government. (2021, March 30). India provides 100,000 doses of COVID-19 vaccines to Fiji. Retrieved on September 1, 2021, from https://www.fiji. gov.fj/Media-Centre/News/INDIA-PROVIDES-100,000-DOSES-OF-COVID19-VACCINES\#: :text=INDIAper cent20PROVIDESper cent20100per cent2C000per cent20DOSESper cent20OFper cent20COVIDper cent2D19per cent20VACCINESper cent20TOper cent20FIJI,-30per cent2F03per cent2F2021\&text=Primeper cent20Ministerper cent20Bainimaramaper cent20saidper cent20the,Fijiper cent20willper cent

Fiji Ministry of Health and Medical Services. (2021a). COVID-19 vaccination. Retrieved on September 1, 2021, from https:/www.health.gov.fj/covid-vaccine/

Fiji Ministry of Health and Medical Services. (2021b). COVID-19 vaccination campaign [Press release]. Retrieved on September 2, 2021, from https:/www.health.gov.fj/ covid-19-vaccination-campaign/

Fiji Ministry of Health and Medical Services. (2021c). Fiji Ministry of Health and Medical Services COVID-19 cases. Retrieved on September 2, 2021, from https:// experience.arcgis.com/experience/db0cf0a2827d4c718a5a9ad823482028

Fiji Ministry of Health and Medical Services. (2021d, April 30). New Zealand to donate 250,000 courses of COVID-19 vaccines to Fiji. Fiji Ministry of Health and Medical Services. Retrieved on May 21, 2021, from http://www.health.gov.fj/newzealand-to-donate-250000-courses-of-covid-19-vaccines-to-fiji/\#: : text=Newper cent20Zealandper cent20hasper cent20offeredper cent2Cper cent20and,Ministerper cent20Ifereimiper cent20Waqainabeteper cent20announcedper cent20today.

Fiji Ministry of Health and Medical Services. (2021e). per cent of Population Vaccinated COVID-19 Dose 2 (Division). Retrieved on September 1, 2021, from https://tupaia. org/supplychain_fiji/FJ/COVID-19per cent20Fiji?overlay=FJ_COVID_TRACKING_Dose_2_District_Percentage_Vaccinated

Fiji Women's Rights Movement. (2021). Rapid Assessment: Fijian Women's perceptions of the COVID-19 vaccine. Retrieved on September 1, 2021, from Suva, Fiji: http://www. fwrm.org.fj/images/COVID19/RapidAssessment_WomenCOVID19Vaccines.pdf

Freeman, D., Loe, B. S., Chadwick, A., Vaccari, C., Waite, F., Rosebrock, L., . . Innoc, S. (2020). COVID-19 vaccine hesitancy in the UK: the Oxford coronavirus explanations, attitudes, and narratives survey (Oceans) II. Psychological Medicine, 1 - 15.

Glaser, B., \& Strauss, A. (1967). The discovery of grounded theory: Strategies for qualitative research. Chicago, IL: Aldine.

Gunaratne, K., Coomes, E. A., \& Haghbayan, H. (2019). Temporal trends in anti-vaccine discourse on twitter. Vaccine, 37(35), 4867-4871.

Hao, K., \& Basu, T. (2020, February 12). The coronavirus is the first true social-media 'infodemic'. MIT Technology Review. Retrieved on September 1, 2021, from https:// www.technologyreview.com/2020/02/12/844851/the-coronavirus-is-the-first-truesocial-media-infodemic/

Islam, A. N., Laato, S., Talukder, S., \& Sutinen, E. (2020). Misinformation sharing and social media fatigue during COVID-19: An affordance and cognitive load perspective. Technological Forecasting and Social Change, 159, 120201.

Islam, M. S., Sarkar, T., Khan, S. H., Kamal, A.-H. M., Hasan, S. M. M., Kabir, A., . . . Chughtai, A. A. (2020). COVID-19-related infodemic and its impact on public health: A global social media analysis. The American Journal of Tropical Medicine and Hygiene, 103(4), 1621-1629.

Jegede, A. S. (2007). What led to the Nigerian boycott of the polio vaccination campaign? PLoS Medicine 4(3), e73.

Josephson, A., \& Lambe, E. (2020, April 2). Brand communications in time of crisis. 
Retrieved on September 1 2021, from https://blog.twitter.com/en_us/topics/company/2020/Brandcommunications-in-time-of-crisis.html

Kant, R., Jorari, L., \& Cain, T. N. (2021). Covid-19 awareness, online discourse, and vaccine distribution in Melanesia: Evidence and analysis from Fiji, Papua New Guinea, and Vanuatu. Retrieved on September 1, 2021, from https://asiafoundation.org/wp-content/uploads/2021/04/Pacific-Islands_Covid-19-awareness-onlinediscourse-and-vaccine-distribution-in-Melanesia.pdf

Kant, R., \& Varea, R. (Forthcoming, 2021). Information disorders: Facebook and the spread of COVID-19 'misinformation' in Fiji. Pacific Journalism Review: Te Koakoa, 27(1-2).

Kouzy, R., Jaoude, J. A., Kraitem, A., Alam, M. B. E., Karam, B., Adib, E., . . Baddour, K. (2020). Coronavirus goes viral: quantifying the COVID-19 misinformation epidemic on Twitter. Cureus., 12, e7255.

Kowalczyk, O., Roszkowski, K., Montane, X., Pawliszak, W., Tylkowski, B., \& Bajek, A. (2020). Religion and faith perception in a pandemic of COVID-19. J Relig Health, 59(6), 2671-2677. https://doi.org/10.1007/s10943-020-01088-3

Kumar, R. (2021). Determinants of COVID-19 vaccine hesitancy in Fiji. Retrieved on September 2, 2021, from https://e.issuu.com/issuu-reader3-embed-files/latest/twittercard.html? $\mathrm{u}=$ dialoguefiji\&d=vaccine_hesitancy_report\&p=4\&fbclid=IwAR1kQ dfngIOieONh-hm2YiiwQiFlCyQFH_fkCLwQ2rzgD8OHw1J4ZMd5nGg

Lake, M. A. (2020). What we know so far: COVID-19 current clinical knowledge and research. Clinical Medicine, 20(2), 124-127.

Lavorgna, L., Ippolito, D., Esposito, S., Tedeschi, G., \& Bonavita, S. (2017). A disease in the age of the web: How to help people with multiple sclerosis in social media interaction. Interactive Journal of Medical Research, 6(2), e18.

Lima, D. L., Lopes, M. A., \& Brito, A. M. (2020). Social media: friend or foe in the COVID-19 pandemic? Clinics., 75, e1953.

Mian, A., \& Khan, S. (2020). Coronavirus: the spread of misinformation. BMC Medicine, 89.

Naidu, J. (2021, April 25). COVID-19: Containment zones in Lami, Suva, Nausori, Lautoka and Nadi For 14 days beginning tomorrow. Fiji Sun. Retrieved on September 1, 2021, from https://fijisun.com.fj/2021/04/25/covid-19-containment-zones-in-lamisuva-nausori-lautoka-and-nadi-for-14-days-beginning-tomorrow/

Ortiz-Ospina, E. (2019, September 18). The rise of social media. Our World in Data. Retrieved on September 12021 , from https://ourworldindata.org/rise-of-social-media.

Posetti, J., \& Bontcheva, K. (2020). Disinfodemic: Dissecting responses to covid-19 disinformation: Policy brief 2. United Nations Educational, Scientific and Cultural Organisation. Retrieved August 22, 2021, from https:/en.unesco.org/sites/default/ files/disinfodemic_dissecting_responses_covid19_disinformation.pdf

Reuters (2021, April $\overline{2}$ ). Fact-check Johnson \& Johnson's COVID-19 vaccine does not contain aborted fetal cells. Reuters Fact Check. Retrieved on September 2, 2021, from https://www.reuters.com/article/factcheck-johnson-aborted-idUSL1N2LU1T9

Robie, D. (2021). (New) Ecological Problems: Post-pandemic Climate Change Remains an Oceania Existential Threat. IKAT: The Indonesian journal of southeast Asian studies, 4(2), 129-143. https://doi.org/10.22146/ikat.v4i2.59677

Robie, D., \& Krishnamurthi, S. (2020). FRONTLINE: The sociology of a pandemic: Countering a COVID 'disinfodemic' with a campus media initiative. Pacific Journalism Review : Te Koakoa, 26(2), 179-200. https://doi.org/10.24135/pjr.v26i2.1131

Seneviratne, K., \& Muppidi, S. R. (2021). COVID-19, racism and politicization: Media in the midst of a pandemic. Cambridge, UK: Cambridge Publishers.

Sunstein, C. R., \& Vermeule, C. A. (2009). Conspiracy theories: Causes and cures. The 
Journal of Political Philosophy, 17(2), 202-227.

Vacala, K. (2021, May 15). Australia commits to providing one million vaccine. Retrieved on September 1, 2021, from https:/www.fbcnews.com.fj/news/covid-19/australiacommits-to-providing-1-million-vaccine/

Waszak, P. M., Kasprzycka-Waszak, W., \& Kubanek, A. (2018). The spread of medical fake news in social media - the pilot quantitative study. Health Policy and Technology., $7(2), 115-118$.

World Health Organisation. (2021, March 6). COVID-19 vaccines shipped by COVAX arrive in Fiji. World Health Organisation (WHO) South Pacific News. Retrieved on September 1, 2021, from https://www.who.int/westernpacific/about/how-we-work/pacificsupport/news/detail/06-03-2021-covid-19-vaccines-shipped-by-covax-arrive-in-fiji

Yuan, X., Schuchard, R. J., \& Crooks, A. T. (2019). Examining emergent communities and social bots within the polarised online vaccination debate in twitter. Social media + Society, 5(3), 1-12.

Romitesh Kant is a Development Leadership Programme (DLP) research associate, and an honorary research associate at the Institute of Human Security and Social Change (IHSSC), La Trobe University, Melbourne, Australia. romit.fj@gmail.com

Rufino Varea is a PhD candidate at the School Agriculture, Geography, Environment, Ocean and Natural Sciences, University of the South Pacific, Suva, Fiji.

Jason Titifanue is a teaching assistant at the School of Law and Social Sciences, University of the South Pacific, Suva, Fiji; a Development Leadership Programme $(D L P)$ research associate; and an honorary research associate at the Institute of Human Security and Social Change (IHSSC), La Trobe University, Melbourne, Australia. 